\title{
Estratégia de proteção de patentes farmacêuticas: o caso do atazanavir
}

\section{The strategy of pharmaceutical patent protection: the case of atazanavir Estrategia de protección de patentes farmacéuticas: el caso de atazanavir}

\author{
Carla Cristina de Freitas da Silveira | carlasilveira@far.fiocruz.br \\ Universidade Estadual do Rio de Janeiro, Instituto de Medicina Social. Rio de Janeiro, RJ, Brasil. \\ Marilena Cordeiro Dias Villela Corrêa | correamarilena@gmail.com \\ Universidade Estadual do Rio de Janeiro, Instituto de Medicina Social. Rio de Janeiro, RJ, Brasil.
}

Wanise Borges Gouvea Barroso | wanise@far.fiocruz.br

Fundação Oswaldo Cruz, Farmanguinhos. Rio de Janeiro, RJ, Brasil.

\section{Resumo}

O alto custo dos medicamentos antirretrovirais (ARVs) justifica estudos sobre estratégias de patenteamento farmacêutico vis-à-vis à política pública brasileira de acesso universal aos ARVs. A análise da evolução das tendências tecnológicas através do estudo de patentes fornece também uma visão dos envolvidos no desenvolvimento de uma tecnologia. Para traçar o perfil de patenteamento do antirretroviral atazanavir, no Brasil e no mundo, foi realizado um estudo na base de dados Thomson Reuters Integrity que identificou o desenvolvimento, produção e comercialização desse produto. Foram identificados 49 documentos de patentes, tendo a proteção dessa tecnologia se iniciado em 1996, com a empresa Novartis e seu licenciado, a Bristol, que reivindicaram proteção para a molécula. Prossegue até 2013, com proteção de invenções incrementais, originárias na China. O estudo possibilitou discutir a importância do sistema de patentes na promoção da inovação, e evidenciar tipos diversos de proteção para um produto e tecnologias relacionadas.

Palavras-chave: Patente; Atazanavir; HIV/Aids; Saúde pública; Propriedade intelectual.

\begin{abstract}
The high costs of antiretroviral drugs (ARVs) justifies studies on pharmaceutical patenting strategies vis-à-vis the Brazilian public policy of universal access to ARVs. The analysis of the evolution of technology trends through patent study also provides an overview of those involved in the development of a technology. To trace the patenting profile of atazanavir antiretroviral in Brazil and in the world, a study was conducted using Thomson Reuters Integrity database and such study identified the development, production and marketing of this product. 49 patent documents were identified, having been started the protection of this technology in 1996 with Novartis and its licensee Bristol, which claimed protection for the molecule. It remains until 2013, with protection of incremental inventions originating in China. The study has allowed to discuss the importance of the patent system to promoting innovation, and to highlight different types of protection for a product and related technologies.
\end{abstract}

Keywords: Patent; Atazanavir; HIV/Aids; Public health; Intellectual property. 


\section{Resumen}

El alto costo de los medicamentos antirretrovirales (ARVs) justifica estudios sobre estrategias de protección de patentes farmacéuticas vis-à-vis la política brasileña de acceso universal a los ARVs. El análisis de la evolución de las tendencias tecnológicas a través del estudio de las patentes posibilita una visión de los diferentes actores responsables por el desarrollo de la tecnologia. Para analizar el perfil de patentamiento del antirretroviral atazanavir en Brasil y en el mundo se realizó un estudio através de la base de datos de Thomson Reuters Integrity a fin de identificar el desarrollo, la producción y comercialización del producto. Fueron identificados 49 documentos de patentes y los resultados muestran que la protección de la tecnologia comienza en 1996 con Novartis y el detentor de su licencia, Bristol, las cuales reivindicaron protección para la molécula. que continúa hasta 2013, con documentos originarios de China, que provienen de invenciones incrementales. El estudio posibilitó discutir la importancia del sistema de patentes para fomentar la innovación y permitir diferentes tipos de protección para un producto y tecnologias relacionadas.

Palabras clave: Patente, Atazanavir; HIV/SIDA; Salud pública; Propiedad intelectual.

\section{Contribuição dos autores}

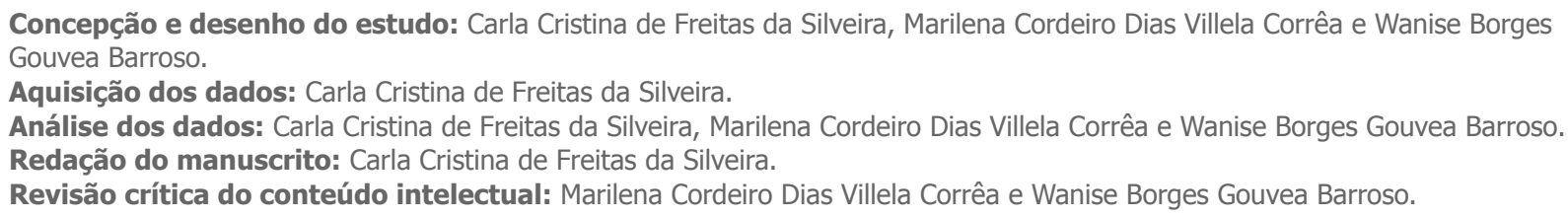

Conflitos de interesse: Não

Fontes de financiamento: Não

Dados abertos da pesquisa: Não

Apresentação anterior: Não

Histórico do artigo: Submetido: 10.nov.2015 | Aceito: 02.dez.2015 | Publicado: 31.mar.2016

Licença: CC BY-NC atribuição não comercial. Com essa licença é permitido acessar, baixar (download), copiar, imprimir, compartilhar, reutilizar e distribuir os artigos, desde que para uso não comercial e com a citação da fonte, conferindo os devidos créditos de autoria e menção à Reciis. Nesses casos, nenhuma permissão é necessária por parte dos autores ou dos editores.

\section{Introdução}

A síndrome da imunodeficiência adquirida - Aids é uma doença pandêmica e, de acordo com o relatório da Organização Mundial da Saúde (OMS) de 2014, afeta 36,9 milhões de pessoas no mundo. Atualmente, vivem com o vírus HIV cerca de 2,6 milhões de crianças (menores de15 anos), 17,4 milhões de mulheres e 34,3 milhões de adultos ${ }^{1}$.

No Brasil, desde o início da epidemia, em 1980, até junho de 2013, foram registrados aproximadamente 680 mil casos de aids. A epidemia continua estável com a taxa de incidência oscilando em torno 
de 20,2 casos de aids por 100 mil habitantes. Em 2012 foram notificados 39.185 novos casos da doença no país, o que, por consequência, propicia uma parcela de mercado extremamente atrativa para a indústria farmacêutica, e, portanto, um dos campos de maior investimento em pesquisa e desenvolvimento (P\&D) e de proteção através de patentes dos medicamentos antirretrovirais (ARVs)².

$\mathrm{O}$ acesso universal e gratuito aos medicamentos ARVs no Brasil consiste em uma política pública prioritária do Departamento de DST ${ }^{\mathrm{i}}$, Aids e Hepatites Virais ${ }^{\text {ii }}$ desde 1996. De acordo com dados de dezembro de 2012, 313 mil pacientes recebem regularmente os medicamentos para tratar aids, que atualmente são divididos em cinco classes ${ }^{\mathrm{iii}}$ e distribuídos pelo Sistema Único de Saúde (SUS) ${ }^{3}$. Aproximadamente 1 bilhão e 200 mil reais são investidos pelo governo federal para o combate às DST/aids. Desse montante, 780 milhões destinam-se ao fornecimento de medicamentos para o tratamento da aids ${ }^{2}$.

Na região das Américas, o número de pessoas em tratamento com ARVs no final de 2013 se aproximou de 800 mil, cerca de 60.000 a mais que em 2012. Como possui 44\% [34-50\%] das pessoas que vivem com HIV e recebem ARVs, a região da América do Sul continua a ser a região com a maior cobertura de ARVs entre os países de baixa e média renda ${ }^{4}$.

O Brasil é um país pioneiro na adoção de políticas de saúde para garantir o acesso universal e gratuito aos medicamentos ARVs. A análise integrada do tema patentes farmacêuticas e acessibilidade aos medicamentos é tarefa extremamente complexa e sob a ótica da política de saúde, verifica-se que, "apesar dos progressos alcançados no Brasil, nas últimas décadas, o compromisso de assegurar a acessibilidade universal aos medicamentos ainda está bastante distante" 5 . No que diz respeito às políticas públicas na área da saúde, a concessão de patentes farmacêuticas passou a provocar inúmeros debates focados no acesso a medicamentos e no direito à saúde.

O medicamento que tem como princípio ativo o composto atazanavir, da classe de inibidor de protease (IP), produzido pelo laboratório Bristol Myers Squibb, sob a marca Reyataz, amplamente utilizado no tratamento dos portadores de HIV, com registro aprovado em 2003 pelo órgão de registro US Food and Drug Administration (FDA), é considerado um medicamento de $2^{\mathrm{a}}$ geração, e sua distribuição gratuita é feita pelo Departamento de DST, Aids e Hepatites Virais, do Ministério da Saúde ${ }^{6}$. Em 2012, o Reyataz encontrava-se entre os três antirretrovirais líderes de vendas globais, dividindo $48 \%$ das vendas no mercado mundial de antirretrovirais com os medicamentos Atripla e Truvada, ambos da Gilead .

Para que determinado produto possa ser produzido ou comercializado em um país torna-se necessário identificar se determinada tecnologia está protegida por patentes. Caso não esteja, deve ser verificado se existem pedidos de patente depositados, e analisar o seu status, de modo a não infringir as patentes, bem como os pedidos de patente com expectativa de proteção.

A realização de estudo que analisa a estratégia de proteção da invenção por patentes possibilita acompanhar a evolução da pesquisa e o desenvolvimento do medicamento, analisar a extensão da proteção, identificar a data de expiração, bem como, auxiliar na elaboração de estratégia de compra ou produção do insumo farmacêutico ativo (IFA) e/ou do medicamento, além de estabelecer a política pública de modo a manter o acesso da população a medicamentos para o tratamento do HIV/Aids.

O preço elevado dos medicamentos ARVs vem suscitando, no cenário internacional, o debate de temas relativos à propriedade intelectual, mais precisamente sobre as patentes farmacêuticas e a sustentabilidade

i DST - Doença sexualmente transmissível.

ii Departamento de DST, Aids e Hepatites Virais: foi criado no Brasil em 1986 e tornou-se referência mundial no tratamento e atenção à aids e a outras doenças sexualmente transmissíveis. Ligado à Secretaria de Vigilância em Saúde do Ministério da Saúde, o Departamento trabalha para reduzir a transmissão do HIV/aids e das hepatites virais e promover a qualidade de vida dos pacientes. [citado 20 set 2014]. Disponível em: http://www.aids.gov.br/pagina/o-que-faz-o-departamento.

iii Classes de medicamentos antirretrovirais: Inibidores Nucleosídeos da Transcriptase Reversa, Inibidores Não Nucleosídeos da Transcriptase Reversa, Inibidores de Protease, Inibidores de Fusão e Inibidores da Integrase. [citado 10 out 2014 ]. Disponível em: http://www.aids.gov.br/pagina/quais-sao-os-antirretrovirais. 
da política de acesso a esses medicamentos. Entre os fatores que contribuem para os elevados preços dos ARVs encontra-se a proteção patentária, uma vez que a patente garante o direito de exclusividade de exploração. As indústrias farmacêuticas alegam que estabelecem preços altos para os medicamentos como forma de obter retorno do investimento feito em P\&D de produtos e processos farmacêuticos, e ameaçam interromper novas pesquisas, caso não vejam seus investimentos em P\&D remunerados da forma como defendem ${ }^{8}$.

O Brasil reformulou a sua legislação de propriedade industrial de modo que fossem previstos na lei os requisitos mínimos dos dispositivos do Acordo TRIPS e assim passou a reconhecer patentes para todos os campos tecnológicos, inclusive o farmacêutico ${ }^{\text {iv }}$. Em 14 de maio de 1996 foi promulgada a Lei $n^{0}$ 9.279, ou seja, a nova Lei da Propriedade Industrial (LPI), que, entre outras mudanças, autorizou o patenteamento de produtos e processos químico-farmacêuticos, anteriormente excluídos de patenteabilidade, além de ampliar o prazo de proteção para 20 anos $^{9}$.

O sistema de patentes no Brasil atende às diretrizes gerais da Convenção da União de Paris (CUP), que estabelecem como regras principais a "independência das patentes", o "tratamento igual para nacionais e estrangeiros" e o "direito de prioridade". Entretanto, apesar da patente se configurar como um importante instrumento de desenvolvimento econômico a ser adotado pelos países com o objetivo de promover o desenvolvimento tecnológico-científico, o seu reconhecimento pode ou não levar a resultados positivos, dependendo dos contextos político e econômico de um determinado país ${ }^{10}$.

Diversas estratégias de patenteamento de medicamento têm sido colocadas em prática pela indústria farmacêutica para que a proteção do mesmo se estenda por mais alguns anos após a expiração da patente básica do composto. A estratégia denominada evergreening tem sido verificada quando a indústria se utiliza do depósito de pedidos de patentes sequenciais de invenções incrementais, visando prolongar o prazo de exclusão dos concorrentes que pretendam comercializar e produzir medicamentos genéricos. A adoção da referida estratégia pelos laboratórios prejudica as políticas públicas do país, uma vez que nos referidos casos não há de fato uma inovação, mas um novo pedido de patente com objetivo de estender por mais tempo o domínio sobre o mercado para aquela molécula inicialmente protegida. Assim, o medicamento de referênciav passa a ser a única opção de compra, sendo vendido a preços elevados, impedindo que a população de menor poder aquisitivo adquira os mesmos, bem como, inviabilizando a compra pelo governo, devido às limitações de orçamento para os programas de saúde ${ }^{11-13}$.

Como o acesso da população a medicamentos está intimamente ligado aos direitos de propriedade intelectual, identifica-se no mercado a ausência de medicamentos com a mesma aplicação terapêutica, bem como as suas respectivas versões genéricas, devido à proteção patentária dos medicamentos requerida pelos laboratórios produtores do medicamento de referência. O que acarreta, algumas vezes, a falta de abastecimento de medicamentos pelo sistema público de saúde, em decorrência dos preços elevados de aquisição, normalmente praticados pelas empresas titulares e fabricantes do medicamento.

Os documentos de patente podem ser utilizados como indicadores no estudo da evolução das tendências tecnológicas relacionadas a um medicamento, bem como, possibilitam uma visão dos diversos atores (depositantes e inventores) responsáveis pelo desenvolvimento de determinada tecnologia. A informação

iv TRIPS (Agreement on Trade-Related Aspects of Intellectual Property Rights) - Acordo sobre Aspectos dos Direitos de Propriedade Intelectual Relacionados ao Comércio): "É um tratado internacional, integrante do conjunto de acordos assinados em 1994 que encerrou a Rodada Uruguai e criou a Organização Mundial do Comércio" (OMC; WTO, na sigla em inglês World Trade Organization). [citado 10 out 2014]. Disponível em: htps://pt.wikipedia.org/wiki/Acordo TRIPs e em: http://www.wto.org/english/ tratop_e/trips_e/t_agm0_e.htm

v "Medicamento de Referência é um produto inovador, registrado no órgão federal responsável pela vigilância sanitária e comercializado no País cuja eficácia, segurança e qualidade foram comprovadas cientificamente junto ao órgão federal competente por ocasião do registro, conforme a definição do inciso XXII, artigo 30, da Lei n. 6.360, de 1976 (com redação dada pela Lei no 9.787 de 10 de fevereiro de 1999)." [citado 30 nov 2015]. Disponível em: http://portal.anvisa.gov.br/wps/content/Anvisa+Portal/ Anvisa/Inicio/Medicamentos/Assunto+de+Interesse/Medicamentos+de+referencia 
descrita nesses documentos é de suma importância, pois permite: a avaliação do estado da técnica de determinada tecnologia; o subsídio à tomada de decisões; a identificação de tecnologias emergentes, as tendências de mercado e a identificação de novos produtos, além de definição de potenciais rotas para aperfeiçoamentos em produtos e processos existentes ${ }^{14}$.

O monitoramento da estratégia de patenteamento de medicamentos realizado pelas empresas, a partir de bases de dados de patentes e de informações contidas nas bases de registro de medicamentos, possibilita traçar estratégias e realizar ajustes de políticas públicas na área da saúde.

A identificação das patentes que protegem determinado medicamento consiste em tarefa complexa, pois as bases de patentes não informam de forma clara quais as patentes que protegem determinado medicamento. Para isso, deve-se buscar o IFA (insumos famacêuticos ativos) ou a marca do medicamento de referência no Orange Book ${ }^{15}$, publicação da agência reguladora de medicamentos dos EUA (FDA - Food and Drug Administration), que lista os números das patentes americanas que protegem a tecnologia dos mesmos. A identificação dos números das patentes é possível, uma vez que a lei reguladora americana exige que sejam listados no Orange Book as patentes que protegem os medicamentos aprovados para a comercialização nos Estados Unidos.

A informação do número das patentes que protegem os medicamentos não é exigida pela agência reguladora de medicamentos brasileira, ou seja, pela Agência Nacional de Vigilância Sanitária (Anvisa) ${ }^{16}$, conforme o faz a FDA. Assim, de modo a se identificar os pedidos de patente ou patentes brasileiros devemse buscar os correspondentes às patentes americanas listados no Orange Book.

Entretanto, para a identificação da estratégia de proteção patentária de determinada tecnologia deve-se realizar o mapeamento dos documentos de patente, através da realização de buscas em bases de dados de patente. Algumas bases de dados estão disponibilizadas de forma gratuita, principalmente aquelas elaboradas e mantidas por escritórios de patente, tais como: INPI (Instituto Nacional da Propriedade Industrial) ${ }^{17}$, USPTO (United States Patent and Trademark Office) ${ }^{18}$ e Espacenet (European Patent Office) ${ }^{19}$. Entretanto, certas bases de dados comerciais disponibilizam campos de busca que possibilitam buscar informação mais precisa, bem como resultados de busca com informações estruturadas e completas, tais como: Questel Orbit ${ }^{20}$, Scifinder ${ }^{21}$ e Thomson Reuters Integrity ${ }^{22}$.

Para a realização de busca, deve-se, inicialmente, selecionar a base de dados adequada ao estudo que será efetuado; identificar as palavras-chave com base no assunto a ser pesquisado; escolher a classificação internacional de patentes; verificar a abrangência de cobertura da base, os mecanismos de busca adequados, o acesso ao conteúdo total do documento e facilidades de exportar, filtrar e analisar os resultados originados da busca, entre outras medidas.

A base de dados Thomson Reuters Integrity, apesar de ser comercial, encontra-se disponível nos Periódicos da Capes $^{23}$ de forma gratuita para universidades e centros de pesquisa brasileiros. Tem como objetivo fornecer informações relacionadas à pesquisa e ao desenvolvimento de medicamentos de interesse. A base de dados integra informações de mais de 420.000 compostos biológicos, químicos e farmacêuticos com atividade biológica demonstrada e mais de $\mathbf{2 3 5 . 0 0 0}$ registros de famílias de patentes. Os dados de patentes, informações regulatórias e press releases disponibilizados nessa base são obtidos a partir de referências da literatura e de patentes dos seguintes escritórios: Escritório de Patentes Europeu (EP), PCT (WO), Japão, Estados Unidos, China, Índia e Coréia, refletindo a atividade de pesquisa e desenvolvimento de medicamentos em todo o mundo, e a respectiva proteção patentária. Não fazem parte dessa base de dados os documentos brasileiros de patentes.

A base de dados de patentes do INPI, disponível no Sistema Integrado da Propriedade Industrial (SINPI), pode ser consultada de forma gratuita e compreende patentes e pedidos de patentes depositados e publicados no Brasil a partir de 1982. Deve ser utilizada quando se deseja conhecer se determinada 
tecnologia encontra-se patenteada ou não no país e também para visualizar o andamento do processo do pedido de patente depositado.

Como a identificação da proteção dos ARVs por patentes no Brasil consiste em um importante instrumento de avaliação e de elaboração de estratégia para o fortalecimento da política nacional de acesso a medicamentos, realizou-se o presente estudo de modo a se identificar o perfil dos documentos de patente do ARV atazanavir, de modo a identificar-se a estratégia de proteção no Brasil, bem como analisar a possibilidade de sua produção em território nacional.

O objetivo do estudo consiste em verificar a estratégia de patenteamento do medicamento ARV atazanavir no Brasil e no mundo, com a finalidade de apresentar o mercado, a pesquisa, o desenvolvimento, a produção e a comercialização para esse medicamento. Assim, por meio desse estudo pretende-se realizar um levantamento do panorama atual dos depósitos de patentes relativas ao atazanavir, a fim de comparar as empresas depositantes, os países, os inventores e perfis das tecnologias desenvolvidas, bem como o impacto dessa proteção por patente na produção do medicamento e no equilíbrio entre os interesses dos titulares das patentes e o interesse público.

\section{Metodologia}

Inicialmente, realizou-se busca no site da Anvisa, de modo a verificar quais as formas farmacêuticas do medicamento atazanavir que possuem registro no Brasil.

Para identificá-las, bem como as patentes americanas que protegem esse medicamento, realizou-se busca pelo nome do insumo farmacêutico ativo no Orange Book, publicação disponível no site do FDA que, como mencionado anteriormente, lista as patentes concedidas nos EUA. Também foi consultada a $15^{\mathrm{a}}$ edição do Merck Index ${ }^{24}$ de modo a identificar a primeira patente concedida para o medicamento.

Para identificar os documentos de patente no Brasil relacionados ao atazanavir, realizou-se busca no Espacenet de modo a recuperar as patentes brasileiras correspondentes às patentes listadas no Orange Book. Após a identificação dos números dos documentos, realizou-se busca na base de dados do INPI para verificar o andamento dos mesmos.

Para estudar a proteção do atazanavir no Brasil, realizou-se busca na base de patentes do INPI no campo de pesquisa avançada, empregando-se as palavras-chave "atazanavir" ou "azapeptídeo" nos campos resumo e título. Também realizou-se busca no campo depositante empregando-se as palavras-chave "Novartis"ou "Bristol", combinadas com as palavras-chave "HIV" ou "AZA" no campo resumo. Foram recuperados um total de sete documentos após purificação e eliminação de redundância.

Para a seleção da base de patentes a ser utilizada de modo a recuperar documentos necessários ao estudo de análise da estratégia de proteção patentária do atazanavir, realizou-se, em janeiro de 2015, busca preliminar dos documentos de patentes nas bases de dados Questel Orbit, Scifinder e Thomson Reuters Integrity, separadamente. A estratégia de busca não foi limitada a um período temporal.

Analisando-se os resultados da busca, através dos resumos e quadros reivindicatórios dos documentos de patente recuperados nas buscas nas três bases de dados, concluiu-se que no presente estudo deveriam ser utilizados apenas os resultados da busca na base de dados Thomson Reuters Integrity, uma vez que ela permite a recuperação de documentos de patente, cujo objeto de invenção compreende essencialmente a pesquisa, desenvolvimento e produção do atazanavir. Os resultados das outras bases de dados (Questel Orbit e Scifinder) não foram considerados relevantes, pois, além de apresentarem os documentos encontrados na Thomson Reuters Integrity, também apresentam documentos que citam apenas o atazanavir, sem que a invenção esteja relacionada ao mesmo. Dessa forma, o estudo não representaria as invenções relacionadas somente ao atazanavir, nos resultados também estariam descritas invenções referentes a outros medicamentos. 
Após a seleção da base de dados Thomson Reuters Integrity, com o objetivo de obter a maior quantidade de documentos relevantes, utilizou-se na estratégia de busca apenas o nome do princípio ativo "atazanavir", sem qualquer restrição relativa ao período. A busca compreendeu o emprego da palavra-chave "atazanavir" no campo de busca rápida, "Quick Access to Key Drugs \& Biologics Information”, e selecionou-se apenas "patentes" como documentos. Após a realização da busca, foram recuperados 50 documentos depois da purificação e eliminação de redundância.

Os resultados encontrados foram exportados da base Thomson Reuters Integrity para um arquivo do Excel, no formato .xlsx. O arquivo exportado compreende vários dados como título, depositante, inventor, número do pedido, data de publicação, data de prioridade, data de expiração da patente, assunto, resumo original e resumo elaborado por especialistas da base Thomson Reuters Integrity, o qual apresenta a novidade, as vantagens e a aplicação da invenção.

Os 50 documentos foram tabulados manualmente e submetidos à leitura e análise de cada item. Esta etapa foi necessária para realizar a depuração dos documentos, a partir da exclusão daqueles não atinentes à matéria objeto do presente estudo. A exclusão foi realizada a partir da leitura do título, resumo original e resumo gerado pela base de dados Thomson Reuters Integrity. Foi excluído um documento, em virtude do seu objeto de invenção não compreender tecnologia relacionada ao atazanavir. Após a referida exclusão, foram analisados os 49 documentos de patente, de forma a compreender melhor a estratégia de proteção dos laboratórios.

Como a base de dados Thomson Reuters Integrity não inclui documentos brasileiros, foi utilizada a base de dados Espacenet para identificar os documentos BR correspondentes aos 49 documentos em estudo.

\section{Resultados e discussão}

Inicialmente, após a busca no site da Anvisa e no Orange Book do FDA, foram identificadas as formas farmacêuticas do medicamento atazanavir que receberam registro. A seguir, analisaram-se os documentos de patente recuperados nas buscas, os quais protegem as inovações relacionadas ao medicamento atazanavir, apresentados a seguir.

\section{Formas farmacêuticas registradas no Brasil pela Anvisa}

De acordo com a busca realizada no site da Anvisa, apenas a Bristol-Myers Squibb e a Fundação Oswaldo Cruz (Fiocruz) possuem registro válido para o Sulfato de Atazanavir em cinco apresentações diferentes. A Bristol possui registro para cápsulas gelatinosas dura de 100, 150, 200 e 300mg e pó para preparações extemporâneas $^{\text {vi }}$ de 50mg/1,5g, e a Fiocruz possui registro para cápsulas gelatinosas duras de 150, 200, e 30omg, conforme detalhado na Quadro 1.

vi Preparação extemporânea: toda preparação para uso em até $48 \mathrm{~h}$ após sua manipulação, sob prescrição médica, com formulação individualizada. [citado 12 set 2014]. Disponível em: http://portal.crfsp.org.br/juridico-sp-42924454/legislacao/2597resolucao-rdc-no-67-de-08-de-outubro-de-2007-anexos-iv-v-e-vi.html 
Quadro 1: Empresas e formas farmacêuticas do atazanavir registradas na Anvisa

\begin{tabular}{|l|l|l|}
\hline Empresa & Nome comercial & Forma de dosagem e apresentação \\
Bristol-Myers Squibb & Reyataz & $100,150,200$ e 300mg; cápsula gelatinosa dura \\
\cline { 3 - 3 } & $50 \mathrm{mg} / 1,5 \mathrm{~g} ;$ pó para preparações extemporâneas \\
\hline Fundação Oswaldo Cruz & Sulfato de Atazanavir & 150,200 e $300 \mathrm{mg} ;$ cápsula gelatinosa dura \\
\hline
\end{tabular}

Fonte: Elaboração própria a partir de dados extraídos do site da ANVISA. Disponível em: http://www.anvisa.gov.br

A concessão do registro do medicamento Sulfato de Atazanavir para a Fundação Oswaldo Cruz foi obtida em 13 de janeiro de 2014 e compreende uma das etapas do processo de Parceria de Desenvolvimento Produtivo (PDP) ${ }^{\text {vii }}$, firmada em novembro de 2011, de cooperação técnico-científica entre a Fiocruz, representada pelo Instituto de Tecnologia em Fármacos - Farmanguinhos - e a sociedade Bristol-Myers Squibb Company visando à transferência de tecnologia do atazanavir, nas dosagens 150, 200 e 300mg, bem como a produção do respectivo insumo farmacêutico ativo - IFA em território nacional. $\mathrm{O}$ acordo inclui a transferência da tecnologia, a fabricação e a distribuição do medicamento pelo período de cinco $\operatorname{anos}^{25}$.

\section{Formas farmacêuticas registradas e patentes listadas no FDA}

Cinco empresas apresentaram solicitação de registro ao FDA para o sulfato de atazanavir e suas associações, conforme listado na Quadro 2. Apenas o laboratório Bristol-Myers Squibb e a Teva Pharms USA possuem registro aprovado no FDA. As demais empresas - Emcure, Matrix e Aurobindo - possuem aprovação provisória e só poderão comercializar o medicamento após o registro final e a expiração da patente nos EUA.

vii Parceria de Desenvolvimento Produtivo (PDP): Parcerias que envolvem a cooperação mediante acordo entre instituições públicas e entre instituições públicas e entidades privadas para desenvolvimento, transferência e absorção de tecnologia, produção, capacitação produtiva e tecnológica do País em produtos estratégicos para atendimento às demandas do SUS. - Art. $2^{\circ}$ da Portaria do Ministério da Saúde - MS no 2.531/2014. 
Quadro 2: Solicitações de registro do Atazanavir no FDA

\begin{tabular}{|l|l|l|l|l|l|}
\hline $\mathbf{N}$ No do pedido & $\begin{array}{l}\text { Ingrediente } \\
\text { ativo } \\
\text { Sulfato de } \\
\text { atazanavir }\end{array}$ & $\begin{array}{l}\text { Forma de } \\
\text { dosagem } \\
\text { Cápsula }\end{array}$ & Apresentação & $\begin{array}{l}\text { Nome } \\
\text { comercial }\end{array}$ & Requerente \\
\hline 200196 & $\begin{array}{l}\text { Sulfato de } \\
\text { atazanavir }\end{array}$ & Cápsula & $300 \mathrm{mg}, 150,200 \mathrm{mg}$ & $\begin{array}{l}\text { Emcure Pharma } \\
\text { (Índia) }\end{array}$ \\
\hline 091611 & $\begin{array}{l}\text { Sulfato de } \\
\text { atazanavir }\end{array}$ & Cápsula & $150 \mathrm{mg}$ & $\begin{array}{l}\text { Emcure Pharma } \\
\text { (Índia) }\end{array}$ \\
\hline 022282 & $\begin{array}{l}\text { Sulfato de } \\
\text { atazanavir; } \\
\text { Ritonavir }\end{array}$ & Comprimido & $300 \mathrm{mg} / 100 \mathrm{mg}$ & - & $\begin{array}{l}\text { Matrix Labs LTD } \\
\text { (Índia) }\end{array}$ \\
\hline 091673 & $\begin{array}{l}\text { Sulfato de } \\
\text { atazanavir }\end{array}$ & Cápsula & $\begin{array}{l}100,150,200, \\
300 \mathrm{mg}\end{array}$ & $\begin{array}{l}\text { Matrix Labs LTD } \\
\text { (Índia) }\end{array}$ \\
\hline 204806 & $\begin{array}{l}\text { Sulfato de } \\
\text { atazanavir }\end{array}$ & Cápsula & $\begin{array}{l}100,150,200, \\
300 \mathrm{mg}\end{array}$ & $\begin{array}{l}\text { Teva Pharms USA } \\
\text { (Israel) }\end{array}$ \\
\hline 021567 & $\begin{array}{l}\text { Sulfato de } \\
\text { atazanavir }\end{array}$ & Cápsula & $\begin{array}{l}100,150,200, \\
300 \mathrm{mg}\end{array}$ & Reyataz & $\begin{array}{l}\text { Aurobindo } \\
\text { Pharma LTD }\end{array}$ \\
\hline 206352 & $\begin{array}{l}\text { Sulfato de } \\
\text { atazanavir }\end{array}$ & Pó & $50 \mathrm{mg} /$ pacote & Reyataz & $\begin{array}{l}\text { Bristol-Myers } \\
\text { Squibb }\end{array}$ \\
\hline 206353 & $\begin{array}{l}\text { Sulfato de } \\
\text { atazanavir; } \\
\text { cobicistat }\end{array}$ & Comprimido & $300 \mathrm{mg} / 150 \mathrm{mg}$ \\
\hline
\end{tabular}

Fonte: Elaboração própria a partir de dados extraídos do site do FDA. Disponível em: http://www.fda.gov/

O medicamento com a substância ativa atazanavir (Reyataz) possui registro no FDA e o laboratório Bristol-Myers Squibb tem autorização para comercializá-lo, em cápsulas de 100, 150, 200 e 300mg e em pó de 50mg/pacote, bem como para o medicamento Evotaz, que consiste em uma associação de atazanavir (30omg) com cobicistat (150mg).

A empresa israelense Teva Pharms USA obteve aprovação do registro para o sulfato de atazanavir em cápsulas de 100, 150, 200 e 300mg em 22 de abril de 2014. Entretanto, em virtude de acordo estabelecido em esfera judicial, a Teva não lançará o seu genérico pelo menos até julho $2017^{26-27}$, ou seja, até que a patente expire.

A empresa indiana Emcure Pharma solicitou inicialmente registro para cápsulas de sulfato de atazanavir em cápsulas de 100, 150 e 200mg e sua aprovação provisória foi concedida em 04 de fevereio de 2008. Posteriormente foi solicitado registro também para cápsulas de 300mg, com aprovação provisória concedida em 19 de agosto de 2010.

Após a solicitação de registro para cápsula de sulfato de atazanavir de 150mg, com aprovação provisória concedida em 15 de setembro de 2010, o laboratório indiano Matrix Labs Ltd solicitou registro para a associação de atazanavir (300mg) com ritonavir (100mg) em comprimido, com aprovação provisória concedida em 18 de novembro de 2011.

A empresa Aurobindo Pharma Ltd solicitou registro para cápsulas de sulfato de atazanavir em cápsulas de 100, 150, 200 e 300mg, com aprovação provisória concedida em 31 de janeiro de 2014. 
O atazanavir foi aprovado pelo FDA em 20 de junho de 2003 para o laboratório Bristol, sendo o primeiro antirretroviral aprovado para administração uma vez ao dia. Estudos revelam que o seu uso não apresenta elevação de colesterol e lipodistrofia como efeito colateral; além de não causar resistência cruzada com outros antirretrovirais. Quando administrado com ritonavir apresenta potencial equivalente ao lopinavir para uso em terapia de resgate em pacientes com um grau de resistência aos medicamentos, embora o uso de ritonavir reduza as suas vantagens metabólicas.

Em 20 de outubro de 2006, o FDA aprovou uma nova formulação de atazanavir (30omg cápsulas) para ser tomado como parte da terapia de combinação de drogas. Esta formulação reduz a carga de comprimidos, pois uma cápsula de 300mg pode substituir duas cápsulas de 150mg.

Para o presente estudo foram consideradas apenas as patentes que protegem o sulfato de atazanavir. As patentes que envolvem as demais formulações farmacêuticas (sulfato de atazanavir + ritonavir e sulfato de atazanavir + cobicistat) não serão discutidas, pois deverão ser objeto de outro estudo.

O Quadro 3 mostra as patentes que protegem o medicamento atazanavir encontradas a partir do Orange Book. As mesmas foram informadas pelo próprio titular da tecnologia por ocasião do registro do medicamentono FDA, órgão de vigilância sanitária norte-americano.

Quadro 3: Patentes do Atazanavir listadas no Orange Book e correspondentes brasileiras

\begin{tabular}{|l|l|c|c|l|}
\hline $\begin{array}{l}\text { Número da } \\
\text { patente }\end{array}$ & $\begin{array}{l}\text { Data de } \\
\text { expiração }\end{array}$ & $\begin{array}{l}\text { Reivindicação de } \\
\text { IFA }\end{array}$ & $\begin{array}{l}\text { Reivindicação de } \\
\text { produto }\end{array}$ & Depositante \\
\hline $\begin{array}{l}\text { US5849911 } \\
\text { (BR9701877) }\end{array}$ & Jun 20, 2017 & X & X & Novartis AG \\
\hline $\begin{array}{l}\text { US6087383 } \\
\text { (BR9814736) }\end{array}$ & Dec 21, 2018 & $x$ & $x$ & Bristol Myers Squibb \\
\hline
\end{tabular}

Fonte: Elaboração própria a partir de dados extraídos do site do FDA. Disponível em: http://www.fda.gov/

A patente US5849911, intitulada “Antivirally Active Heterocyclic Azahezane Derivatives", teve o seu pedido depositado em o9 de abril de 1997 e foi concedida em 15 de dezembro de 1998. Os compostos reivindicados na patente compreendem inibidores de aspartato-protease retroviral, suas propriedades farmacodinâmicas são excelentes e podem ser utilizados, por exemplo, no tratamento da aids. Apesar da titularidade da patente US5849911 ser da Novartis, o desenvolvimento do atazanavir foi licenciado para a Bristol-Myers Squibb ${ }^{28,29}$. A patente US5849911 é correspondente a três outras patentes, as US6110946, US6166004 e US6300519, uma vez que reivindicam o mesmo pedido prioritário, em que essas reivindicam composto, composição e processo, respectivamente.

A segunda patente US6087383, concedida em 11 de julho de 2000, foi depositada em 21 de dezembro de 1998, sob o título: "Bisulfate salt of HIV protease inhibitor", e a matéria reivindicada compreende o sal cristalino de bissulfato de atazanavir, o qual apresenta elevada taxa de solubilidade/dissolução e biodisponibilidade oral quando comparado à forma de base livre deste composto HIV azapeptido inibidor de protease.

Comentários referentes às patentes BR9701877 e BR9814736, correspondentes às patentes US5849911 e US6087383, respectivamente, serão discutidos posteriormente. 


\section{Patentes citadas pelo Merck Index}

Identificaram-se, através do Merck Index, o pedido de patente W09936404 e a patente americana correspondente US5849911, que foi a primeira concedida e que protege o composto e o medicamento atazanavir; tais documentos são de titularidade da Novartis, informação que coincide com a do Orange Book do FDA.

O bissulfato de atazanavir foi reivindicado no pedido de patente WO9936404, que corresponde à patente americana US6087383, ambos de titularidade da Bristol-Myers Squibb, a qual também foi informada ao FDA.

A análise do primeiro pedido depositado é de grande relevância no estudo do cenário de patentes, uma vez que possibilita indicar quem e quando a tecnologia foi inicialmente desenvolvida.

\section{Patentes correspondentes no Brasil}

A patente brasileira BR9701877, concedida em 28 de setembro de 2004, é correspondente à patente US5849911. A matéria protegida no Brasil consiste de compostos, processo para a sua preparação, composições farmacêuticas e uso no tratamento para uma doença retroviral. Como a patente BR9701877 possui validade até 22 de abril de 2017, de modo a não infringir os direitos patentários, a produção e comercialização do atazanavir no Brasil por terceiros só poderá ocorrer após essa data.

O pedido de patente brasileiro BR9814736 é correspondente à patente US6087383. O mesmo foi indeferido em 31 de março de 2009 e reivindicava proteção para o sal bissulfato de atazanavir.

Dessa forma, em virtude do indeferimento do pedido brasileiro BR9814736, o referido sal de bissulfato cristalino do atazanavir encontra-se em domínio público no Brasil enquanto o atazanavir base livre está protegido pela BR9701877.

\section{Panorama global}

Após a realização da busca e recuperação dos documentos de patente referentes ao medicamento atazanavir na base de dados Thomson Reuters Integrity, analisou-se o cenário do desenvolvimento tecnológico no nível mundial.

\section{Depósitos por ano de prioridade}

A Figura 1 apresenta o perfil dos depósitos dos pedidos de patente do atazanavir recuperados na base Thomson Reuters Integrity. A proteção das tecnologias relacionadas ao atazanavir se inicia em 1996 com a proteção do composto pela Novartis e perdura até 2013 com diversas outras formas de proteção, como processos, formulações, polimorfos e associações requeridas por depositantes distintos. 


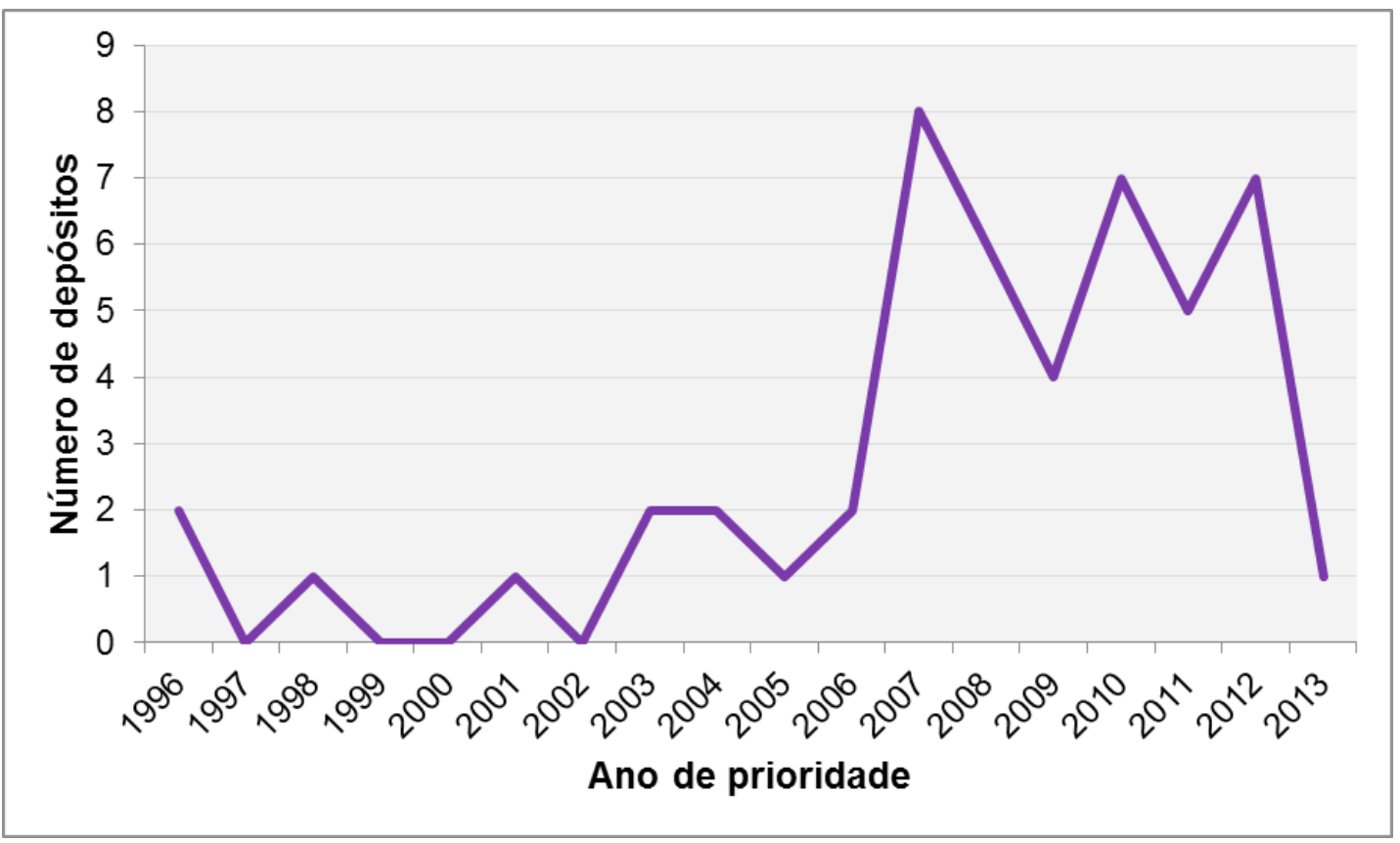

Figura 1: Perfil dos depósitos dos pedidos de patente Fonte: Elaboração própria a partir de dados extraídos da base Thomson Reuters Integrity. Disponível em: http:// thomsonreuters.com/integrity/

Observa-se um crescimento expressivo no número de depósitos de pedidos de patente a partir do ano de 2007, o qual ocorre praticamente no período de 10 anos após o depósito da patente que originou o medicamento. O longo intervalo de tempo para o surgimento de novos depósitos provavelmente é decorrente da exclusividade temporal no mercado do titular da tecnologia originária, bem como da espera dos concorrentes pela comprovação de custo-efetividade do medicamento, atreladas ao início da pesquisa e desenvolvimento de novas formas de proteção para a referida molécula.

Cabe destacar que, entre os pedidos depositados em 2007, metade é de titularidade da Bristol-Myers Squibb e reivindicam formas de dosagem e composição. Os demais pedidos de patente no período foram depositados pelas empresas Gilead, Mylan, Cipla e Concert Pharmaceuticals, os quais revindicam proteção para combinação, composição e derivados de azapepitídeo.

É importante ressaltar que os pedidos de patente permanecem em sigilo por um período de 18 meses. Portanto, quaisquer documentos de patente depositados nos últimos 18 meses encontram-se em sigilo, não tendo sido possível a sua recuperação no levantamento realizado.

\section{Formas de proteção}

A Figura 2 apresenta as formas de proteção reivindicadas através da linha do tempo. Após a leitura do conjunto de reivindicações dos documentos de patentes coletados, observa-se que o portfólio de patentes do atazanavir possui proteção diversificada, com cobertura em 10 áreas de especialização, como síntese, processos, produto, composições, combinações, polimorfos, uso, biomarcadores e nanotecnologia. 


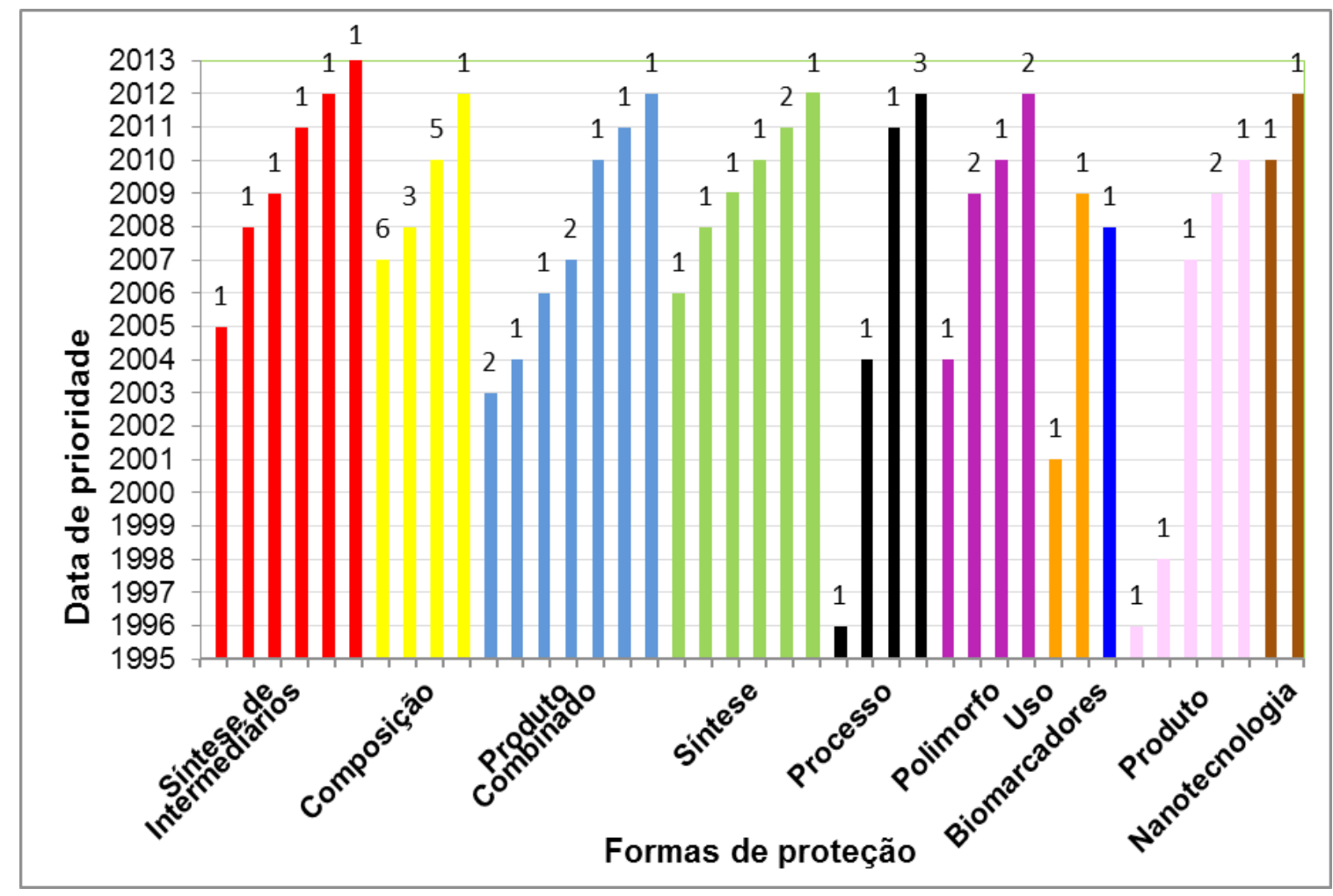

Figura 2: Perfil das formas de proteção

Fonte: Elaboração própria a partir de dados extraídos da base Thomson Reuters Integrity. Disponível em: http:// thomsonreuters.com/integrity/

Em 1996 foi reivindicada proteção para a molécula e processo de preparação do atazanavir e dois anos mais tarde, em 1998, um novo pedido reivindica o bissulfato de atazanavir, garantindo a estratégia de proteção e o monopólio sobre a tecnologia.

Quando se analisam as diversas formas de proteção das patentes, observa-se uma maior incidência de pedidos para composição, com 15 pedidos (25\%) reivindicados entre os anos de 2007 e 2012. Destacam-se também, no período entre 2003 e 2012, nove pedidos de patente (15\%) associados à combinação do atazanavir com outros agentes antirretrovirais protegidos, como apricitabina, maraviroc, ritonavir, elvitegravir, amprenavir, nelfinavir e compostos antimaláricos quinolínicos, de forma de melhorar o efeito anti-HIV.

Nos anos de 2004, 2009, 2010 e 2012 foram depositados seis pedidos (10\%) de inovações farmacêuticas incrementais, que reivindicam novas formas polimórficas para o sulfato e bissulfato de atazanavir com propriedades de dissolução, biodisponibilidade e estabilidade melhoradas.

Os últimos pedidos de patente depositados em 2012 e 2013 também são inovações farmacêuticas incrementais e reivindicam método de preparação de novos cristais de bissulfato de atazanavir e método de preparação biológica de intermediários de atazanavir.

Os pedidos de patente que envolvem nanotecnologia, depositados em 2010 e 2012, compreendem composições e métodos de liberação na célula, através dos quais o ingrediente farmacêutico ativo é incorporado no interior dos canais de nanoporos das partículas.

O pedido de patente de 2008 referente a biomarcadores reivindica proteção para sistemas e kits úteis na estratificação dos indivíduos submetidos à terapia com o medicamento atazanavir e predição de segurança, toxicidade e/ou eficácia do medicamento. 


\section{Pedidos depositados por país}

A análise dos documentos de patente por país (Figura 3) revela que os Estados Unidos figuram como o país com o maior número de depósitos, com 21 documentos de patente. O que significa dizer que, do total de 49 documentos recuperados na busca, 42,8\% de depósitos são provenientes dos Estados Unidos, seguidos pela Índia e China, com 10 depósitos (20,4\%) e 7 depósitos (14,2\%), respectivamente. É importante destacar que os pedidos de patente depositados no Brasil não foram contabilizados nesta análise, uma vez que a base Thomson Reuters Integrity não disponibiliza os pedidos brasileiros.

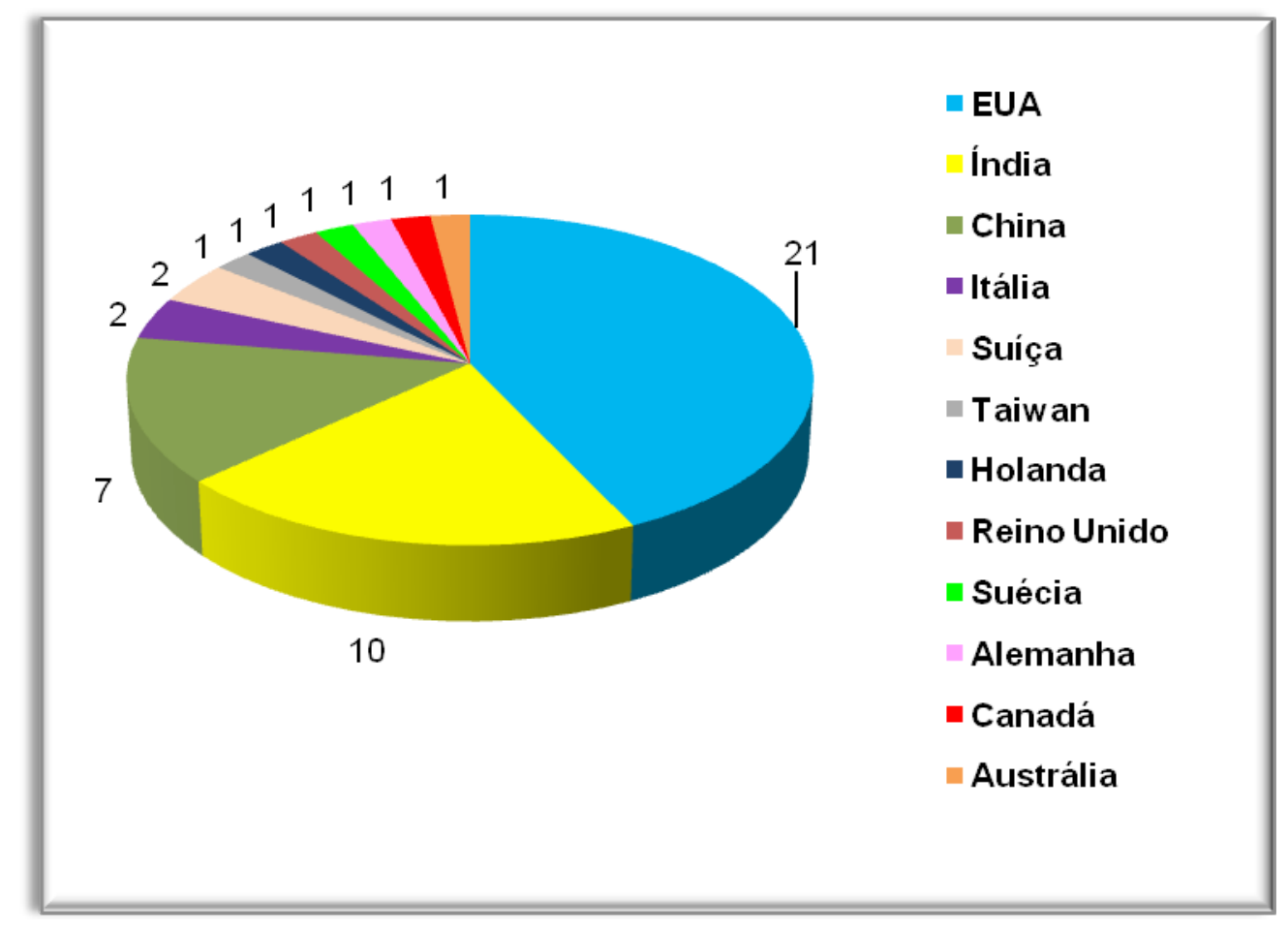

Figura 3: Documentos de patente por país

Fonte: Elaboração própria a partir de dados extraídos da base de dados Thomson Reuters Integrity. Disponível em: http:// thomsonreuters.com/integrity/

O crescimento do número de depósitos de patentes por países como China e Índia pode ser explicado pela introdução tardia do regime de patenteamento de produto farmacêutico nessses países; além disso, políticas de incentivo pautadas na melhoria de processos e produtos, com a utilização do aperfeiçoamento incremental que partem para criar variações de produtos existentes, intensivos em alta tecnologia, para se adaptar a cenários locais, melhorar a qualidade e reduzir custos também contribuem para tal crescimento.

\section{Depositantes}

A Figura 4 apresenta o número de documentos de patente por empresas. A análise das empresas depositantes possibilita a identificação dos concorrentes e possíveis parceiros com interesse comum no desenvolvimento da tecnologia. Observa-se que a titularidade das patentes é diferenciada ao longo do ciclo de patenteamento do medicamento, com diferentes participantes no desenvolvimento da droga, começando com o titular, Novartis e seu licenciado Bristol-Myers Squibb, que originou a composição, totalizando 12 documentos de patentes. 


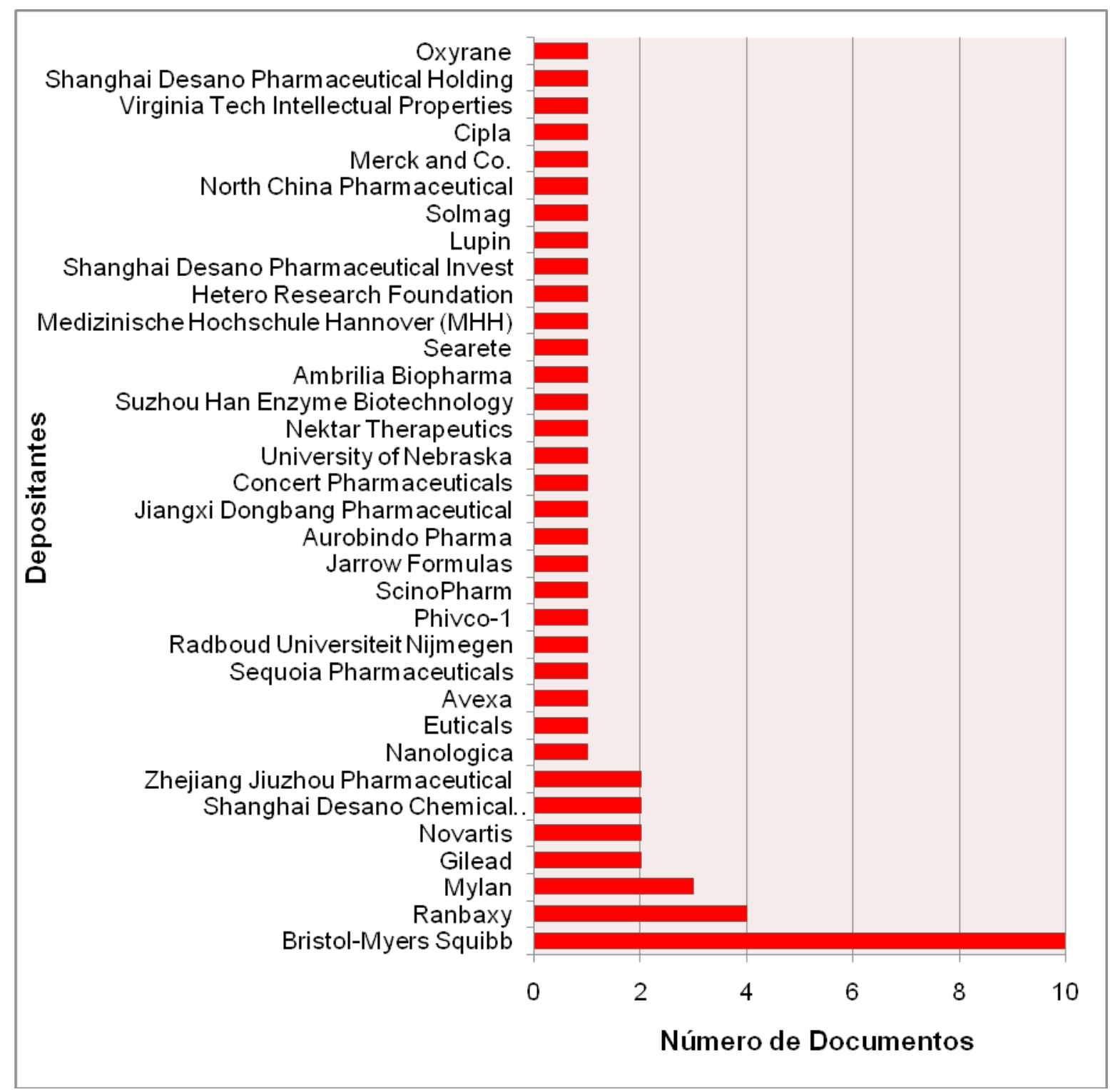

Figure 4: Número de documentos de patente por depositantes

Fonte: Elaboração própria a partir de dados extraídos da base Thomson Reuters Integrity. Disponível em: http:// thomsonreuters.com/integrity/

Entre os demais depositantes e licenciados, destaca-se a empresa Ranbaxy, com quatro documentos que protegem polimorfos, processos de obtenção, intermediários e formulação. Não foram observados inventores isolados como depositante; todos os documentos apresentam inventores ligados às empresas, universidades ou centros de pesquisa.

A leitura dos documentos também permitiu identificar que os principais pesquisadores-inventores, O.M.Y.Koo, F. Nikfar, e S. Diaz, atuantes no desenvolvimento das tecnologias relacionadas ao atazanavir estão diretamente ligados à Bristol-Myers Squibb.

Entre os demais titulares de patentes do atazanavir, há uma maior incidência de pedidos depositados por instituições da China e Índia, países que buscam disputar o mercado mundial, com medicamentos mais baratos e possibilitar o acesso ao tratamento de doenças como o câncer e a aids. Os documentos de patentes foram depositados principalmente após 2010 e reivindicam proteção para novos processos de preparação, terapia combinada, novas formas polimórficas e composições farmacêuticas. 
O destaque das instituições chinesas e indianas como novos atores em potencial, assim como as ameaças da entrada dos genéricos em mercados emergentes como uma oportunidade importante para a saúde pública são informações que corroboraram o posicionamento, por parte da Bristol-Myers Squibb, de adotar a iniciativa de estratégias de preços que permitam versões de baixo custo do atazanavir nos países em desenvolvimento com alto índice de HIV.

\section{Licenciamento do atazanavir}

Em fevereiro de 2006, a Bristol-Myers Squibb licenciou voluntariamente para duas empresas de medicamentos genéricos, Emcure Pharmaceuticals Ltd da Índia, e Aspen Pharma Care da África do Sul, a produção do medicamento atanazavir ${ }^{30}$. Foi permitido às empresas definir seu próprio preço para a droga, o que deve torná-la muito mais acessível para países em desenvolvimento. Um passo positivo no sentido de tornar mais barato o tratamento de $2^{\text {a }}$ geração, além de contribuir para uma maior responsabilidade corporativa de grandes empresas farmacêuticas.

Como consequência do licenciamento voluntário da Bristol-Myers Squib, em fevereiro de 2008, foi concedida "aprovação provisória" no FDA para a versão genérica do atazanavir produzida pela Emcure para uso na África subsaariana e na Índia. Em março de 2014, a Emcure recebeu "aprovação provisória" do FDA para a sua coformulação de atazanavir e um agente potenciador ${ }^{31}$.

Em 2010, as farmacêuticas Bristol-Myers Squibb Co e Novartis Corp. estabeleceram uma disputa de patentes com a Teva Pharmaceuticals Inc sob alegação de infração patentária. De acordo com o relato, a empresa Teva tentou introduzir uma versão genérica do medicamento Reyataz antes de patentes do medicamento expirarem, em junho de 2017. A disputa resultou em acordo, em circunstâncias não reveladas, no qual a Teva concordou em não lançar o seu genérico, pelo menos até julho $2017^{26,27}$.

Em 12 de dezembro de 2013, o Medicines Patent Pool (MPP), organização apoiada pelas Nações Unidas, fundada em 2010 pela Unitaid para aumentar o acesso ao tratamento do HIV e estimular a inovação no mundo inteiro, e a Bristol-Myers Squibb assinaram um acordo de licenciamento para o atazanavir. Este foi o primeiro acordo do MPP para a cobertura de uma terapia de $2^{\text {a }}$ geração preferida pela OMS. Sob os termos do acordo, um pacote de transferência de tecnologia será fornecido para as sublicenciadas de forma a facilitar a produção do atazanavir. Assim, os royalties não serão aplicáveis na maioria dos países e não serão cobrados para os produtos pediátricos. Qualquer royalty que for recolhido no âmbito do referido acordo de licença será reinvestido em grupos locais de HIV/Aids nesses países ${ }^{32}$.

Observam-se que as iniciativas e estratégias mencionadas, adotadas pela Bristol-Myers Squibb nos últimos anos, foram realizadas considerando-se a evolução dos pedidos de patentes na Índia e China. Em termos práticos, a entrada de novos atores no perfil de patenteamento do medicamento referência pode resultar na adoção de medidas positivas para as políticas de acesso aos medicamentos.

\section{Evergreening}

Através da Figura 5 observa-se o tipo de proteção requerida nas patentes pela empresa Bristol e aquelas licenciadas pela Novartis. Os pedidos prioritários que compreendem o início da proteção da tecnologia do atazanavir foram depositados em 1996 e 1997 e são de titularidade da Novartis AG. A Bristol-Myers Squibb dá continuidade à estratégia de proteção a partir de 1998, com a patente do bissulfato de atazanavir. 


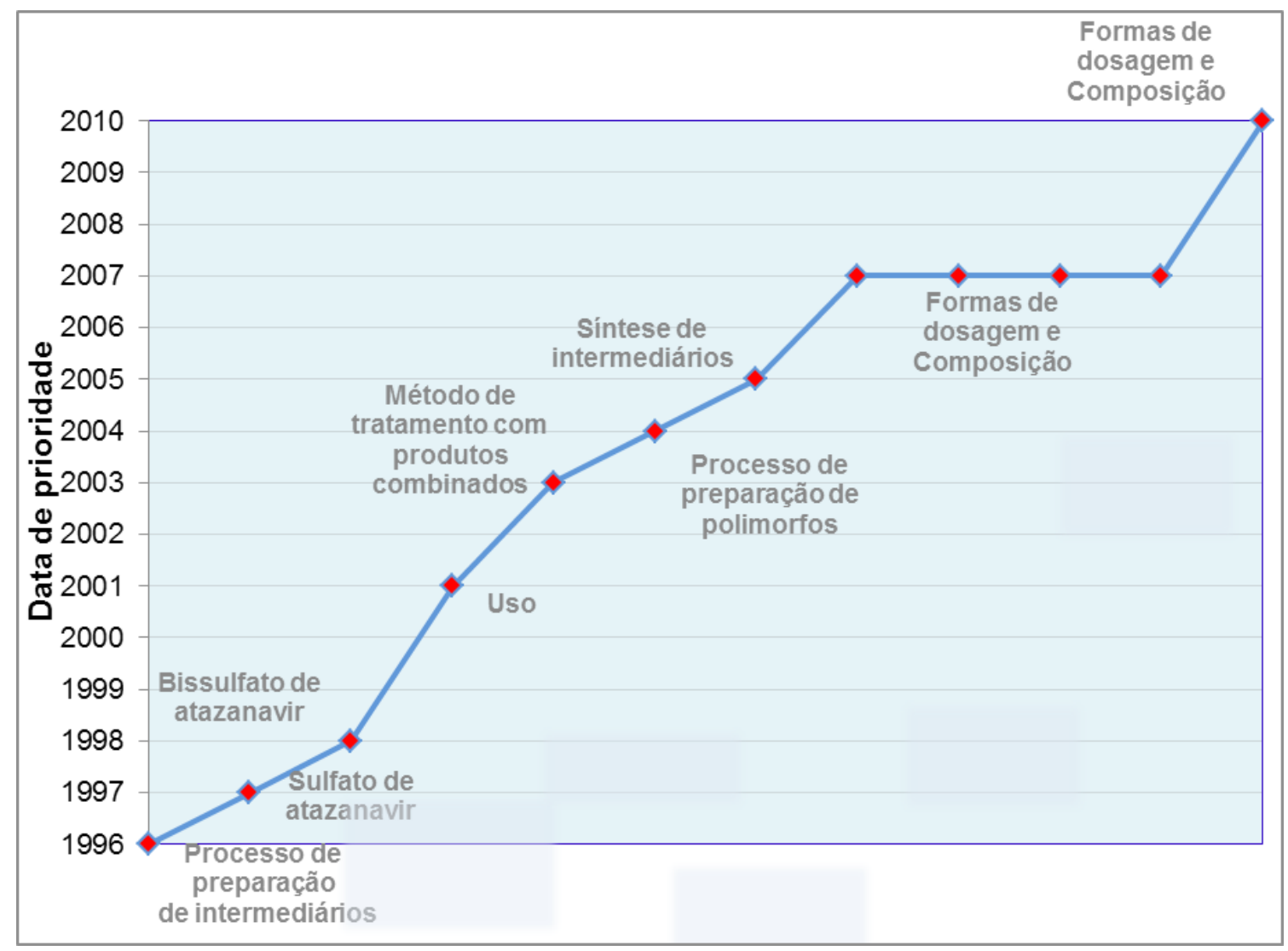

Figura 5: Formas de proteção da Bristol e Novartis

Fonte: Elaboração própria a partir de dados extraídos da base Thomson Reuters Integrity. Disponível em: http:// thomsonreuters.com/integrity/

Na sequência, entre 2001 e 2005 são depositados pedidos de patente de uso, método de tratamento, processo e síntese de intermediários. Os pedidos de patentes depositados em 2007 reivindicam proteção para composições que compreendem o atazanavir e os ARVs abacavir, raltegravir e ritonavir. O último pedido depositado em 2010 reivindica comprimidos contendo sulfato de atazanavir e um agente acidificante, opcionalmente com outro agente ativo, por exemplo, agentes anti-HIV e, opcionalmente, com agentes retardadores de precipitação.

A análise do perfil patentário da Bristol-Myers Squibb possibilita identificar os indícios da prática de evergreening e visualizar como as empresas trabalham no desenvolvimento incremental das tecnologias existentes e utilizam esse artifício como barreira de entrada aos concorrentes. A atuação ocorre mediante proteção de mercados, estendendo direitos de monopólio, impedindo a entrada de concorrentes em determinados campos e, como consequência, causa a inibição da inovação.

Somente após a publicação dos pedidos de patentes da Bristol-Myers Squibb, que compreende o pedido do medicamento referência, no qual se baseia o desenvolvimento subsequente, é que as demais empresas iniciam suas pesquisas. Dessa forma, enquanto o pedido se encontra em sigilo, a empresa possui uma vantagem competitiva frente às demais atuantes no mercado. 


\section{Documentos de patente no Brasil}

No Brasil, de acordo com a base do INPI, foram depositados sete pedidos por laboratórios estrangeiros, envolvendo a tecnologia do atazanavir (Tabela 4).

Quadro 4: Lista de pedidos de patente depositados no Brasil

\begin{tabular}{|c|c|c|c|}
\hline Processo & Depositante & $\begin{array}{l}\text { Data de Depósito/ } \\
\text { Andamento }\end{array}$ & Título \\
\hline BR9701877-5 & $\begin{array}{l}\text { Novartis AG (Novartis SA) } \\
\text { (Novartis Inc.) }\end{array}$ & $\begin{array}{l}\text { 22/04/1997 } \\
\text { Concedido }\end{array}$ & $\begin{array}{l}\text { Derivados de aza-hexano } \\
\text { heterocíclicos antiviralmente ativos, } \\
\text { bem como composição farmacêutica } \\
\text { compreendendo os mesmos. }\end{array}$ \\
\hline BR9814736-6 & Bristol-Myers Squibb Company & \begin{tabular}{|l|}
$22 / 12 / 1998$ \\
Indeferido
\end{tabular} & $\begin{array}{l}\text { Sal de bissulfato, e, forma de } \\
\text { dosagem farmacêutica. }\end{array}$ \\
\hline BR0211544-1 & Bristol-Myers Squibb Company & $\begin{array}{l}21 / 08 / 2002 \\
\text { Arquivado }\end{array}$ & $\begin{array}{l}\text { Emprego de atazanavir na terapia de } \\
\text { HIV. }\end{array}$ \\
\hline BR0509595-6 & Bristol-Myers Squibb Company & $\begin{array}{l}\text { 03/05/2005 } \\
\text { Publicado }\end{array}$ & $\begin{array}{l}\text { Processo para a preparação } \\
\text { de bissulfato de atazanavir, } \\
\text { composto, formulação farmacêutica } \\
\text { compreendendo os mesmos e uso. }\end{array}$ \\
\hline BR0518741-9 & Merck Sharp \& Dohme Corp. & $\begin{array}{l}\text { 02/12/2005 } \\
\text { Arquivado }\end{array}$ & $\begin{array}{l}\text { Uso de uma combinação de uma } \\
\text { droga diretamente metabolizada } \\
\text { por UGT1A1 ou um seu sal } \\
\text { farmaceuticamente aceitável } \\
\text { e atazanavir ou um seu sal } \\
\text { farmaceuticamente aceitável. } \\
\end{array}$ \\
\hline BR0813911-3 & Concert Pharmaceuticals Inc. & $\begin{array}{l}12 / 06 / 2008 \\
\text { Publicado }\end{array}$ & $\begin{array}{l}\text { Composto derivado de azapeptídeos } \\
\text { e composição farmacêutica contendo } \\
\text { o mesmo. }\end{array}$ \\
\hline $\begin{array}{l}\text { BR0823520-1 } \\
\text { (Pedido Dividido do } \\
\text { BR0813911-3) }\end{array}$ & Concert Pharmaceuticals Inc. & $\begin{array}{l}12 / 06 / 2008 \\
\text { Publicado }\end{array}$ & $\begin{array}{l}\text { Composto derivado de azapeptídeos } \\
\text { e composição farmacêutica contendo } \\
\text { o mesmo. }\end{array}$ \\
\hline
\end{tabular}

Fonte: Elaboração própria a partir de dados extraídos do site do INPI. Disponível em: http://www.inpi.gov.br./

A única patente concedida, BR9701877-5, é de titularidade da Novartis e compreende derivados de aza -hexano heterocíclicos antiviralmente ativos, bem como sua composição farmacêutica, que inclui o sulfato de atazanavir.

O pedido de patente BR9814736-6 que solicitava proteção para o bissulfato de atazanavir foi indeferido e, portanto, encontra-se em domínio público no Brasil.

Os pedidos BRo211544-1 e BRo518741-9 foram arquivados e, portanto, também encontram-se em domínio público no Brasil.

Os demais pedidos, BR0509595-6, BRo813911-3 e BR0823520-1 estão aguardando exame no INPI.

Entre os pedidos que aguardam exame no INPI, o BR0509595-6 apresenta como reivindicação o processo para preparar uma nova forma polimórfica do atazanavir e os pedidos BRo813911-3 e BRo823520-1 reivindicam novos compostos de azapeptídeos que são derivados de sulfato de atazanavir, bem como suas composições. Os três pedidos também configuram inovações incrementais que compreendem aperfeiçoamentos ou melhoramentos em tecnologias existentes e já estabelecidas no estado da técnica para o atazanavir. 
O patenteamento dessas inovações possibilitaria uma extensão dos direitos conferidos pela patente de referência e poderia causar impacto no mercado de medicamentos genéricos e no interesse público de acesso a medicamentos.

\section{Conclusões}

O FDA só concede o registro para o laboratório que possui a patente do medicamento ou para as empresas que possuem acordo, com a empresa detentora da patente, de transferência de tecnologia. Para os laboratórios que não possuem a patente, é concedida aprovação de registro provisória e o genérico só poderá ser produzido e comercializado após expiração da patente.

O atazanavir foi registrado no Brasil pela Bristol, detentora da patente e pela Fundação Oswaldo Cruz em virtude do processo de Parceria de Desenvolvimento Produtivo (PDP).

O atazanavir está protegido no Brasil até 22 de abril de 2017, data na qual a patente BR9701877 expira. Somente após essa data, a produção e comercialização do atazanavir poderão ser realizadas por terceiros.

O pedido de patente brasileiro BR9814736 foi indeferido e, portanto, o sal de bissulfato cristalino do atazanavir encontra-se em domínio público no Brasil.

Deve ser estudada a validade da patente em cada país, pois a data de expiração pode ser diferente de um para o outro, dependendo da análise realizada. Ainda que haja patente, é possível o licenciamento voluntário, que levará à redução de preços, em data próxima à de expiração da patente.

O sistema de patentes, criado para promover a inovação, possibilita diversos tipos de proteção, permitindo que uma mesma molécula obtenha outros tipos de proteção por patente através de melhorias desenvolvidas por pesquisas posteriores.

As patentes são ricas fontes de informação tecnológica e neste estudo revelaram-se como importante instrumento norteador do desenvolvimento e produção do atazanavir. Entretanto, a sua utilização como indicador tecnológico deve ser usada com muita cautela devido à diferença na legislação dos diferentes países.

Para certificar-se de que os documentos de patentes identificados na busca realizada nas bases de dados incluem documentos relacionados com a droga em estudo, deve considerar-se a leitura do resumo e quadro reivindicatório desses documentos, uma vez que em alguns casos podem ocorrer erros de tradução ou erros de indexação nas bases de dados.

De acordo com o perfil de evolução dos depósitos de patentes, a proteção se inicia a partir de 1996 e se mantém até 2013, com expressiva participação da China e Índia nos últimos anos. O que reflete uma busca da disputa pelo mercado mundial, com medicamentos mais baratos e acesso ao tratamento de aids com custos reduzidos. Os últimos pedidos depositados pelas empresas chinesas reivindicam método de preparação de novos polimorfos do bissulfato de atazanavir.

No que se refere aos países nos quais se originam a tecnologia patenteada, o estudo revela que a proteção não ocorre apenas no país de prioridade, mas também em outros países, onde se espera requerer a proteção para o produto ou se deseja produzi-lo ou comercializá-lo. Pelo resultado obtido, não foi observado o domínio de uma única empresa.

Observa-se um crescimento expressivo no número de depósitos de pedidos de patente a partir do ano de 2007, com reivindicação de proteção para formas de dosagem, composição, combinação e derivados de azapepitídeo, que são patentes incrementais.

O portfólio de documentos de patente da Bristol-Myers Squibb, titular da primeira patente do bissulfato de atazanavir, compreende pedidos que reivindicam proteção para processos de obtenção de intermediários e novas formulações, indicativo de que o propósito direto é aumentar o escopo de proteção e garantir que terceiros não sejam concorrentes para sua tecnologia. 
A metodologia adotada no presente estudo pode ser empregada para avaliar o perfil patentário de outros medicamentos. Estudo semelhante deve ser realizado quando se deseja produzir ou realizar a transferência de tecnologia dos medicamentos protegidos por patente.

As formas de proteção incrementais identificadas no perfil dos documentos depositados no Brasil apresentam um custo para sociedade e para a política de acesso a medicamento, fatos que poderão ser revertidos no futuro, com a evolução tecnológica nacional, mas o que no momento ainda não é uma realidade.

\section{Referências}

1. $\quad$ Organização Mundial de Saúde. Global Summary of the HIV/AIDS epidemic. WHO; December 2014. [citado 28 jul 2015]. Disponível em: http://www.who.int/hiv/data/epi core july2015.png?ua=1

2. MS/Departamento de DST/AIDS. Boletim Epidemiológico AIDS-DST. 2013. [citado 20 out 2014]. Disponível em: http://www.aids.gov.br/sites/default/files/anexos/publicacao/2013/55559/_p boletim 2013 internet pdf $p$ 51315.pdf

3. MS/Departamento de DST, AIDS e Hepatites Virais. Medicamentos Antirretrovirais. [citado 20 set 2014]. Disponível em: http://www.aids.gov.br/pagina/medicamentos-antirretrovirais

4. Organização Mundial de Saúde. Global Update on the Health Sector Response to HIV. WHO; July 2014. [citado 2 dez 2014]. Disponível em: http://www.who.int/hiv/pub/global-update.pdf

5. Marques MB. Patentes farmacêuticas e acessibilidade aos medicamentos no Brasil. História, Ciências, Saúde - Manguinhos 7 (1): 07-21, mar-jun; 2000. [citado 10 fev 2015]. Disponível em: http://www. scielo.br/scielo.php?script=sci arttext\&pid=S0104-59702000000200001\&lng=en\&tlng=pt. 10.1590/ $\underline{\text { S0104-59702000000200001 }}$

6. Thomson Reuters IP Solutions, IP Consulting Group. Patent Landscape Report Project on Atazanavir. WIPO, nov; 2011.

7. IMS Health. HIV Antivirals Worldwide. 2013. [citado 25 out 2014]. Disponível em: http://www.imshealth. com/deployedfiles/imshealth/Global/EMEA/Germany Austria/Press\%20Room/TOP\%20Line\%20 Market\%20Data/Infografiken/Infografiken\%202013\%20pdf\%20und\%20ppt/2013 12 IMS Infograph World\%20AIDS-Day.pdf

8. Soares JM. Direitos de propriedade intelectual e saúde pública: das normas de regulação às práticas de exame de patentes na área farmacêutica no Brasil. [tese]. Rio de Janeiro: Universidade Estadual do Rio de Janeiro, Instituto de Medicina Social; 2011.

9. Nogueira TS. Licenciamento compulsório e acesso ao tratamento do HIV/AIDS no Brasil. [dissertação]. Rio de Janeiro: Escola Nacional de Saúde Pública Sergio Arouca; 2013.

10. Guimarães ERDB. Direito à saúde e propriedade intelectual de medicamentos no Brasil: a anuência prévia da Agência Nacional de Vigilância Sanitária. [dissertação]. Rio de Janeiro: Universidade Estadual do Rio de Janeiro, Instituto de Medicina Social; 2008.

11. Silveira CCF, Corrêa MCDV, Barroso WBG. Estudo do perfil patentário do Atazanavir. In: Anais do $8^{\circ}$ Encontro Nacional de Inovação em Fármacos e. Medicamentos - ENIFarMed; Sessão de Pôsteres; 2014 set 8-9; São Paulo, Brasil. São Paulo: Editora Teatral; 2014. p. 15.

12. Zalfa VMA, Reis ALA, Gemal AL. Análise dos pedidos de patentes depositados no Brasil para comprimidos de liberação modificada. Prolongamento da proteção patentária. Rev Bras Farm 2010; 91 (1): 46-57.

13. Lima DMM, Silveira CCF. O patenteamento de polimorfos na indústria farmacêutica e o acesso a medicamentos. Physis Rev de Saúde Coletiva 2011; 21 (4): 1515-1536.

14. Soares JM, Corrêa MCDV. Como pesquisar o perfil patentário de um fármaco: o caso Efavirenz. Quím Nova 2010; 33 (5): 1216-1219.

15. FDA - US Food and Drug Administration. Electronic Orange Book: Approved Drug Products with Therapeutic Equivalence Evaluations. [cited 2014 jul 4]. Available from: http://www.fda.gov/

16. ANVISA - Agência Nacional de Vigilância Sanitária. [citado 4 jul 2014]. Disponível em: http://www. anvisa.gov.br

17. INPI - Instituto Nacional da Propriedade Industrial. [citado 7 jan 2015]. Disponível em: http://www.inpi.gov.br 
18. USPTO - United States Patent and Trademark Office. [citado 5 jan 2015]. Disponível em: http://www. uspto.gov/

19. Espacenet - European Patent Office. [citado 5 jan 2015]. Disponível em: https://www.epo.org/ searching/free/espacenet.html

20. Questel Orbit. Base de Dados. [citado 5 jan 2015]. Disponível em: http://www.orbit.com/

21. Scifinder. Base de Dados. [citado 5 jan 2015]. Disponível em: http://www.periodicos.capes.gov.br

22. Thomson Reuters Integrity. Base de Dados. [citado 5 jan 2015]. Disponível em: http://thomsonreuters. com/integrity/

23. Portal de Periódicos da CAPES. [citado 4 jul 2014]. Disponível em: http://www.periodicos.capes.gov.br

24. The Merck Index. 15 ed. New Jersey: Royal Society of Chemistry; 2013.

25. Portal Fiocruz. HIV/Aids: Fiocruz dá novo passo para a produção do antirretroviral Atazanavir. [citado 22 jan 2014]. Disponível em: https://portal.fiocruz.br/pt-br/content/instituto-de-tencologia-em-farmacosproduzira-sulfato-de-atazanavir

26. LAW360. Bristol-Myers, Novartis Settle with Teva Over HIV Drug IP. [cited 2014 jun 4]. Disponível em: http://www.law360.com/articles/155163/bms-novartis-sue-teva-over-hiv-drug-reyataz

27. Patent Docs - Biotech \& Pharma Patent Law \& News Blog. Court Report. [acesso em 04 jun 2014]. Disponível em: http://www.patentdocs.org/2010/03/cou.html

28. Witherell, G. PubMed. BMS-232632 (Novartis/Bristol-Myers Squibb). Curr Opin Investig Drugs. 2001 Mar; 2(3):340-7. [citado 4 set 2014]. Disponível em: http://www.ncbi.nlm.nih.gov/pubmed/11575702

29. Bristol-Myers Squibb. As Fronteiras da Ciência. [citado 5 set 2014]. Disponível em: http://www.bristol. com.br/Files/Com.\%20Corp.\%20-\%20Brochura\%20Instituc.\%20Intranet.pdf

30. AVERT.organizador. Bristol-Myers Squibb gives voluntary license to generic firms. [cited 2014 mar 10]. Avaiable from: http://www.avert.org/news/bristol-myers-squibb-gives-voluntary-license-generic-firms

31. Bristol-Myers Squibb. Patents, Licensing and Technology Transfer: Working with Generic Companies and other Partners. [cited 2014 mar 10]. Avaiable from: http://www.bms.com/responsibility/access-tomedicines/Pages/patents-licensing-technology.aspx

32. Médicos Sem Fronteiras. Conditions of Offer. [citado 4 maio 2014]. Disponível em: http://www. msfaccess.org/sites/default/files/UTW 17 ConditionsOfOffer.pdf 